\title{
Crafting a local-global nexus in the Australian wine industry
}

\author{
David Aylward \\ Michael Clements
}

\section{Research Paper}

\section{Structured Abstract}

\section{Purpose}

To examines strategies that have locked the Australian wine industry into a pricesensitive, commodity wine market. The paper will explain the inherent weakness of these strategies and their inability to address current challenges and opportunities.

\section{Design/methodology/Approach}

The paper uses empirical research data gathered from 100 SME wine firms. These firms were selected using a stratified random sampling technique. Four states were covered New South Wales, Victoria, South Australia and Western Australia - with all major wine regions in these states equally represented. There was careful sampling according to size, so that boutique, small and medium-sized firms were represented. Non-exporting firms were excluded. In each case either the CEO or the Marketing Manager was interviewed.

\section{Findings}

The findings confirm the paper's hypothesis, that increasingly the Australian wine industry has become risk-averse and locked into paradigms and organizational frameworks that are disconnecting from users and their requirements. The findings concur that greater differentiation of place, product, supply chains, and markets is 
required if the industry is to operate effectively within a multidimensional landscape and continue to attract sustainable returns.

\section{Research limitations}

The paper was based largely upon user perceptions about current and future industry developments. It would be extremely valuable if future research could align these perceptions with performance data at industry and firm level to provide a more convincing map of R\&D activity.

\section{Practical implications}

This paper has significant implications and policy advice for future industry organization. The most immediate and important of these is a strategy of emphasizing differentiated, regionally-identified products that target higher price-points in major markets. The industry has already indicated that it intends moving in this direction.

\section{What is original/value of the paper}

The original aspect of the paper is its organization ecology approach to the industry, in which national parameters are replaced by a perception of global operating landscapes. In this sense, users are not only participants, but also spectators and interpreters. The paper should be of value to researchers, policy-makers and all industry stakeholders.

\section{Keywords: Wine industry, differentiation, regionality, risk aversion, supply chain} management, innovation. 


\section{Introduction}

The Australian wine industry is currently at a crossroads, both organizationally and culturally. Its considerable success over the past three decades is casting a long shadow over current operations. Rather than adapting to new and multiple operating pathways of a global wine landscape, the industry’s governing organizations remain risk averse, adhering to the restrictive pathways of previous achievement.

This paper examines strategies that have locked the Australian wine industry into a pricesensitive, commodity wine market. Such strategies, the paper will show, arise from a developing culture of risk aversion within the industry which the paper will address issue detail through an organizational ecology framework. Using empirical data fro 100 SME wine firms it will explain the inherent weakness of these strategies and their inability to address current challenges and opportunities. The paper demonstrates why a differentiated, localized approach to wine production and supply is the most likely strategy for survival.

A key hypothesis in the paper is one of differentiation, allowing for competition of product, rather than price, as the customer moves from 'value' to 'quality and distinctiveness'.

\section{Recent development}

Over the past decade the Australian wine industry has undergone profound changes. Most of these changes have resulted from the industry's organizational responses to global wine trends. 
By the mid-1990s the industry had cemented its global reputation as a leader in the New World's ‘new wave' of innovative wine producers. A bold vision as well as a reconfiguration of infrastructure, resources, marketing, and R\&D was changing the sector's status from that of a cottage industry to a respected participant in international markets. The organizational model behind this transition was one of centralization. It redefined the operating parameters of the industry and established an innovative base from which global growth targets could be met and exceeded.

By the end of the millennium, the Australian wine industry hosted approximately 1,300 producers and ranked as the world's $4^{\text {th }}$ largest exporter with an income of close to $\$ 1.5$ billion per annum (Winetitles, 2001). It also dominated the commodity markets in both the UK and the USA with a large number of best-selling wines. Such success was reflected in imitations by other New World producers, including South Africa, Chile and Argentina. It was also reflected in technology transfer from Australia to other producing countries in the form of direct foreign investment and 'flying winemakers' (Anderson, 2004).

\section{Path dependency from success}

A closer appraisal of these organizational trends and developments, however, uncovers some concerning elements. As predicted by Hannan and Freeman (1984) paths of success often become entrenched to an extent that 'dependency' is established. DiMaggio \& Powell (1991) refer to this path dependency as the 'iron cage of inertia', in which past 
success creates rigid parameters of behaviour that constrict alternative action. As stakeholders adhere to pathways of success they gain security and recognition. Familiarity and success provide barriers to future divergence. Even as the external environment changes and installs new challenges and opportunities, organizations remain reluctant to change existing behaviour (DiMaggio \& Powell, 1991). Adaptability, therefore, is increasingly restricted, allowing a culture of inertia to emerge. Such inertia also has severe consequences for most forms of differentiation, a concept that will be expanded upon later in the paper.

The 'dichotomous' relationship within the Australian wine industry between past success and current risk aversion is centered within the theories of organizational change and inertia. Throughout the 1990s, dominance by Australian wine in major international markets confirmed the industry's benchmarks of success, but also led to a further tightening of its behavioural parameters. Success in these markets was occurring in very specific price points - the commodity sector, where average bottle prices ranged between \$US3 and \$US7.

By 2002, when export volume and export value indices diverged for the first time in almost a decade, it was becoming apparent that existing strategies were faltering. Industry organizations identified the ‘exponential growth’ in winery numbers as the problem. They argued that the influx of new and largely inexperienced vintners was the primary cause of an increasing grape supply and the consequent pressure on prices (WFA, GWRDC, AWBC, 2006). Such interpretations were only partially correct. The 
problem was not that there were too many producers, but rather, too many of these producers were competing in the price-sensitive commodity sector.

This was in line with the continuing encouragement by industry organizations to adhere to the 'Brand Australia' image (GWRDC, 2007). Multi-region production, R\&D, marketing, and distribution were focused on selling the world an Australian product. It was a generic branding which necessarily undermined a product, regional and, most importantly, cultural differentiation. The industry's organizational framework and the multinationals that dominated its landscape, demanded a national, undifferentiated framework.

\section{Cultivating risk aversion}

In 2007, the industry's responses remain largely unchanged. What has been added is the claim that the international wine industry is cyclical and Australia is just one of many producers experiencing a glut. In fact, the past five years offer a detailed case history of cultivated risk aversion in the Australian wine sector. In 2007 its supply and demand equation is even more unbalanced. Export volumes are steadily increasing while value per unit continues to decline. (Supply Chain Review, 2007). Further, “more than $80 \%$ of the volume growth in Australia's wine exports is in bulk rather than bottled form” (Sharp, 2007).

Data from a national survey of 100 wineries, upon which this paper is based, will show that this situation is not the result of a cyclical over-supply of grapes. Rather, it is the 
consequence of the industry's reliance on a saturated commodity sector to which the Australian wine industry has largely been relegated. There are, in fact, price sectors in the industry where, for more than a decade, demand has exceeded supply. Simply put, these sectors have never experienced a surplus. The survey data will show that producers operating at these higher price points remain unable to meet demand, and as a result, price per unit continues to increase. Their success can be attributed largely to differentiation.

Any option for sustainability requires a 'global set-perspective’ (Astley, 1984, 1985; Trist, 1983). This allows for a recognition and acceptance of the changing global wine landscape, and a shift in focus from national frameworks and priorities to the more flexible contours of region-specific production, distribution and marketing (Croser, 2004). In short, a cultural, even anthropological embrace of the product's vitality, variety and differentiated properties is now required (Wilson, 2004; Johnson, 2006).

\section{Why Differentiate?}

In their examination of the New Zealand wine industry, Barker, Lewis and Moran (2001) emphasize the inextricable link between differentiation and quality, a paradigm based on product rather than price competition. They argue that in a differentiated environment “quality becomes (the) predominant discourse of knowledge creation” (p.207) and further, that "discourses of quality (are) linked to place” (p.215). Wilson (2004) captures the variable frameworks of differentiation eloquently when he states that 
“...the process of differentiation in which alcohol and its consumption are so important are themselves processes of globalization, in that they involve the recognition that some things, and some behaviours, set us apart from others in the world"...(p.2).

This statement refers to a differentiation not just of the product, but of its entire cultural fabric. Differentiation ranges from the grape variety selected, to the single-vineyard planting techniques, the harvesting methods, the vinification, the regional identification, the distribution, marketing and finally, the consumption. It is the protection of the product's identity in every step of this supply chain that separates it and its heritage from the rest of the market (Beverland, 2005; Taplin, 2006).The survey findings in this paper will show that the majority of Australia's smaller wine producers also believe strongly in the benefits of differentiation.

Across a global landscape of wine production and consumption, it is the contours in the landscape that allow the industry to evolve. Without such contours, patterns of behaviour remain static, there is little expansion of organizational parameters and finally, what Hugh Johnson (2006) describes as “...charisma in a bottle” becomes a rather bland, multi-regional product mix.

\section{Methodology}

The paper was developed in two phases. The first phase was based upon literature reviews concerning the Australian and international wine industries and discordant developments within these industries over the past decade. Reviews were conducted within the context of the transition from an under-supply of wine grapes in the late 1990s 
to the current over-supply with specific attention on emerging responses to this transition, how these strategies differ, and which appear to be the more effective.

In addition to reviews, the structure of the current paper emerged from consistent findings within the author's previous studies on the wine industry. These findings provided a cohesive set of indicators suggesting a major shift in operating paradigms and a subsequent lack of organizational adaptation by industry organizations.

Phase Two of the study was based on a survey designed around these themes. The intention of the survey was to test the organizational change and inertia themes among small and medium-sized firms in the context of the current wine grape surplus. The survey was also designed to 'unpack' notions of differentiation and contrast its practice with the industry’s current operating framework.

Of the 112 firms approached, 100 small and medium-sized wine operators agreed to be interviewed by phone. These firms were selected using a stratified random sampling technique. Four states were covered - New South Wales, Victoria, South Australia and Western Australia - with all major wine regions in these states equally represented. There was careful sampling according to size, so that boutique, small and medium-sized firms were represented. Non-exporting firms were excluded. In each case either the CEO or the Marketing Manager was interviewed. 
Survey questions were primarily designed for Likert-scale responses (1-5) but were also supplemented with open-ended, qualitative questions. These questions were designed to investigate some of the more detailed issues concerning respondent thought on regionalization, current R\&D extension, and localized branding.

\section{Findings of the study}

A key hypothesis in the paper is one of differentiation, allowing for competition of product, rather than price, as the customer moves from 'value' to ‘quality and distinctiveness’ (Kaniovski, 2005; Benfratello, Piacenza \& Saccetto, 2004). In this context wine producers were asked a series of questions about the effect of the current surplus on their operations, and strategies they had implemented as a response. The answers provided a snapshot of two competing and somewhat contradictory strategies.

The effect of the current wine surplus on operations

Responses to this first issue set parameters for the remainder of the survey. All 100 wine producers were asked how the current surplus was affecting the viability of their operations (See Table 1 below).

Table 1: Impact of wine surplus on firm operations $(n=100)$

\begin{tabular}{|l|c|}
\hline Degree of Impact on Operations & Percentage \\
\hline No Impact & 23 \\
\hline Slight Impact & 34 \\
\hline Moderate Impact & 24 \\
\hline Significant Impact & 12 \\
\hline Threatening Survival & 7 \\
\hline
\end{tabular}

As shown in the Table 1, there was a fairly even distribution across impact categories. If responses are grouped into 'little or no impact' and 'moderate to severe impact' we see that currently $43 \%$ of survey respondents are experiencing real difficulties as a result of 
the wine surplus. The figure certainly indicates that at an industry level a large percentage of small and medium-sized firms are experiencing moderate to severe problems.

It becomes more interesting when the impact categories are disaggregated and used as a basis for comparison with other variables. For example, of the $23 \%$ who claimed there was 'no impact' on their operations, only one operator stated that export value had fallen (by 10\%) in the past 12 months. Of the remaining, 48\% claimed that export value had not been affected while $26 \%$ claimed it had actually increased by $10-15 \%$. Five respondents did not answer the question. For firms in this category there is a clear association between their resilience to the wine surplus and the continued success of exports. From the tables below, the reader can see the continuity of this relationship between each category of impact and export status.

Table 2: Association between effect of wine surplus and export status - firm categories

\begin{tabular}{|l|l|c|}
\hline Impact of wine surplus & Export Value Status & $\begin{array}{c}\text { Percentage } \\
\text { of firms }\end{array}$ \\
\hline No Impact (23\%) & Export value fallen & $4 \%$ \\
\hline & Export value unaffected & $48 \%$ \\
\hline Slight Negative Impact (34\%) & Export value increased & $26 \%$ \\
\hline & Moderate fall in export value & $21 \%$ \\
\hline Export value unaffected & $65 \%$ \\
\hline & Export value increased & $9 \%$ \\
\hline Significant Negative Impact (12\%) & $\begin{array}{l}\text { Significant fall in export } \\
\text { value }\end{array}$ & $50 \%$ \\
\hline & Export value unaffected & $25 \%$ \\
\hline & value \\
\hline Threaticant fall in export & $16 \%$ \\
\hline & Export value unaffected & $67 \%$ \\
\hline & Export value increased & $17 \%$ \\
\hline & $\begin{array}{l}\text { Significant fall in export } \\
\text { value }\end{array}$ & $43 \%$ \\
\hline & Export value unaffected & $29 \%$ \\
\hline & Export value increased & $14 \%$ \\
\hline
\end{tabular}

For survey respondents Table 2 demonstrates that there is an association between the negative impact of wine surplus on firm operations and the value of their exports. While firms that experienced no impact from the surplus demonstrated unaffected or increased export value, those firms that experienced a moderate to significant negative impact from 
the surplus also experienced a moderate to significant fall in the value of their exports. This relationship suggests that there is, in fact, a causal effect between impact on operations and the ability to extract export value from products.

Association between price points, differentiation and competitive advantage The causal effect becomes even more prominent when export FOB prices are examined. Firms were asked to identify average price points they target in export markets, with responses being measured against the original 'categories of impact'. Results (as shown in tables 2 and 3) confirm a clear association between resilience to the wine surplus, export value and the export price points into which the product is sold.

Table 3: Association between impact of surplus and export price points

\begin{tabular}{|l|c|}
\hline Impact Category & $\begin{array}{c}\text { Average FOB price } \\
\text { per case }\end{array}$ \\
\hline No Impact & $\$ 212$ \\
\hline Slight Negative Impact & $\$ 114$ \\
\hline Moderate Negative Impact & $\$ 109$ \\
\hline Significant negative Impact & $\$ 92$ \\
\hline Threatening Survival & $\$ 84$ \\
\hline
\end{tabular}

What is also represented in these data is the probable cause and effect between export price category - commodity, premium or icon - and resilience to an industry wine surplus. As an iconic producer typically stated when asked about the surplus: "What surplus? There is certainly no surplus at the prices points I sell at. I'm struggling to meet the demand".

At the other end of the spectrum, producers feeling most threatened by the surplus were reacting by lowering their export prices even further. In many cases producers admitted that this was an act of desperation, but it also highlights the extent to which the 'commodity culture' has become entrenched among lower-end producers. To add to the situation's gravity, is the fact that while product sell-prices are in decline, operating and distribution costs remain static. This is because commodity markets are volume 
dependent, whereas the premium products can adjust their supply chain costs and promote quality at the expense of the customer.

This 'iron cage' is particularly relevant to the smaller and medium producers. In the 1990s these producers 'piggy-backed' on the export drive of Australia's wine multinationals. They were led into a global market that was thirsty for new, technically faultless products from the New World. The benefit to the smaller producers was immediate and significant. Within several years their markets had increased substantially in geographic spread and number. They sold more and more of their product abroad and so eventually restructured the product and the taste to the requirements of a less discerning, less interested international customer (Croser, 2004, 2006).

It was, however, a market that the large wine producers continued to dominate. The smaller firms occupied a tiny proportion of this market and as more of them flooded it the supply became bloated, with returns shrinking. A critical marker in the fortunes of these smaller producers was the period in which their exports overtook domestic sales. Their traditional customers, who demanded and paid for a wine of distinction based on single vineyard grape selection with strong regional characteristics and hand-crafted attention, were increasingly sacrificed to the bland demands of commodity-style drinkers in the UK and USA. The smaller firms were never going to match the mass plantings, and marketing influence of their multinational 'mentors'. Unfortunately, however, they were matching their character-free wine styles. 
Like their French counterparts in Bordeaux or their New World rivals in New Zealand and the Napa and Sonoma regions of California, Australia's small producers must return to a path of greater differentiation and regionally-focused identity if they are to create sustainable futures. Survey respondents were in agreement with this strategy, with 91\% arguing that regional differentiation of product, identity and culture was intricately linked to an enhanced reputation for wine quality. A snapshot of the Bordeaux garagistes and their product sales reveals that their small-batch, hand-crafted products continue to sell out at prices of 6,000 Euros a case, despite a continued global wine surplus (Echikson, 2004).

Similarly, producers from New Zealand's Marlborough region command record prices for their wine, while the New Zealand wine sector, as a whole, is the only New World industry where demand is still greater than supply. The latest figures from California also provide strong indication that selling into the higher, differentiated price points is the optimum strategy. In April 2007, Bloomberg revealed that US exports (95\% derived from California) had 'soared 30\% in value' while only increasing $4 \%$ in volume, almost a complete reversal of Australia's March 2007 figures where exports increased only 4\% in value and $11 \%$ in volume (Mariani, 2007).

For this strategy of greater differentiation to mature, however, there must be an industryled acknowledgement of the emerging and radically different operational paradigm. The Australian industry must unlock its priorities from the single-sector perspective that dominated its thinking over the past three decades. It must undertake essential 
reconfiguration of product manufacturing, $R \& D$, identity, branding and marketing that is now required by a dual-sector approach becoming evident in other New and Old World countries.

\section{Rebuilding competitive advantage}

In an environment in which the demand for \$212 cases outstrips supply, yet \$84 cases (table 3) cannot attract buyers, the current operating paradigm is clearly failing. Producers of these $\$ 212$ cases are usually successful operators delivering a meticulously hand-crafted product with a distinct heritage and strong regional identity. Yet culturally, they remain isolated within what they see as an ambiguous, nationally-branded industry. For example, when asked about the importance of regional differentiation to their operations, $78 \%$ of these producers claimed it was 'significant' or 'critical', yet $74 \%$ argued that there was no recognition of, or support for, this differentiation by industry bodies.

Within an industry that boasts one of the world's best academies (Roseworthy), a leading R\&D institute (the Australian Wine Research Institute), a heritage of innovation and an almost perfect growing climate the potential for wines of distinction is perhaps without parallel. What are missing, however, are a cultural acceptance and a willingness to adapt. An innovative environment now requires the participative collaboration between supply chain partners, with a focus on the quality discerning customer. In turn this will provide the producer team with scope to craft a premium product, drawing together the existing expertise of industry professionals within regional boundaries. Regional-based identities 
can then utilize a multi-dimensional supply chain to deliver direct to niche markets, at a margin that equates risk with return.

A rebuilding of the Australian wine industry's competitive advantage requires more than the current rhetoric about regional priorities and understanding changing consumer preferences. It requires leadership from industry bodies such as the Grape and Wine Research Development Corporation, the Australian Wine and Brandy Corporation and the Winemakers Federation of Australia. This leadership should be based on competitive advantage for each sector of the industry, not simply those sectors dominated by multinationals. Specifically, this requires five major reconfigurations.

\section{Board restructures}

Boards of major decision-making bodies such as the GWRDC, the WFA, the AWBC and the WEC have been dominated by an 'inner-circle’ of policy makers. Largely, it comprises CEOs of Australia’s major wine corporations, CEOs of the organizations that are in part funded by these corporations (through levies) and selected individuals whose thoughts on industry directions are considered 'appropriate'. In fact, it would be fair to say that the policies emerging from these boards over the past three decades have correlated closely with the economic interests of Australia's larger wine corporations.

Although some attempt at democratizing these boards has taken place over the last two years, greater representation of each of the industry's sectors is required. This could be achieved by expanding board membership to include representation from each major 
regional association. Not only would this diffuse the concentration of interests, but it would also instill a regionalized culture into the decision-making process. Smaller and medium-sized firms would receive greater representation through their elected board member, but possibly of equal importance, the current nationalized culture of resourcing and prioritizing would gradually give way to a regional perspective.

\section{Levy collection}

As mentioned, under the current system and particularly in relation to $R \& D$, those who produce the most, pay the most in levies and therefore, either explicitly or implicitly, exert the most influence on decision-making. The current levy structure ensures a path dependency. Alternative and innovative strategies will always be peripheral to those currently underwritten by the largest stakeholders. Change and adaptability, therefore, are only possible where benefits to the larger stakeholders are obvious. In the Australian wine industry, regional differentiation is not considered beneficial to those corporations that dominate the commodity sector. In fact, it is considered a threat.

In order to create a truly representative levy system, stakeholder voting power and R\&D extension would need to be linked to a specified production level (tonnage), rather than an individual contribution. This would allow for regional cooperatives of smaller producers to match production and, therefore, levy levels of their larger counterparts. It would ensure greater participation in the decision-making process and also more representative extension of the industry's research and development. 


\section{$R \& D$ extension}

R\&D extension within the Australian wine industry is critical to a more differentiated, competitive sector. It was the national platform of R\&D in the 1980s that provided the impetus and capacity for the industry's transformation. It will be the regionalization of this $R \& D$ in the new millennium that will allow the industry to adapt to a multidimensional landscape of production, distribution and marketing. Progression away from supply chains as primarily 'distribution channels' to a new role of as a framework for inter-organizational collaboration and relationship development encourages an innovative environment for world class $R \& D$ which is regionally relevant.

Within the current, national R\&D grid, priorities are set in South Australia. As the hub of the wine industry, this is where all national associations are located, where the national boards meet and consequently, where R\&D extension policy is formulated. In 2007, industry organizations are likely to argue that $\mathrm{R} \& \mathrm{D}$ extension has evolved considerably. They could correctly contend that a centralized R\&D model has been largely replaced by one based around regional extension programs. Reform, in response to industry-wide pressure, is indeed taking place. Yet this new model will lack the capacity to revitalize the industry unless it is linked to robust and well-resourced regional associations. In its present form the extension programs are still prescribed under centralized (South Australian) R\&D priorities (GWRDC, 2007).

As many respondents pointed out, the R\&D priorities of South Australia are not necessarily the R\&D priorities of their region. In fact, $66 \%$ of the survey’s respondents 
claimed that the industry's current R\&D framework provided 'little' or 'no' value to their operations. Soil management, canopy management, disease and pest control, climatic responses and grape variety differ markedly from one region to the next. In short, different regions have different terroirs.

What is required for R\&D flexibility and responsiveness, is a 'hub and spoke' model, whereby regional wine-makers and grape-grower associations link directly in terms of decision-making and resources to the national bodies. Resourced with R\&D field officers, proportionate funds as collected in levies from their region, mandates to differentiate their research needs and a seat on the board of the GWRDC, these associations would deliver tailored R\&D extension to their own region. Such extension would not only enhance a region's innovative capacity but, again, underpin the identity and marketing of that region. It was also the type of extension that was strongly supported by survey respondents. Of those responding to this issue ( $n=92), 87 \%$ believed that the current R\&D framework needs to be significantly more regionalized.

\section{Marketing}

Smaller and medium-sized producers eager to differentiate themselves in export markets are arguing for greater sophistication of the current marketing strategy, claiming 'Brand Australia' gives the impression that all Australian wine comes from the 'same barrel'.

'Brand Australia' is now a twenty-year-old advertising campaign. In fact, critics from Australia’s major market - the UK - facetiously claim it could be more appropriately 
labeled as ‘Bland Australia’ (Heijbroek, 2006; Henry, 2006). These views are reinforced by the survey's respondents; 51\% claimed that the campaign was actually undermining their competitive advantage in international markets. In its current format the marketing campaign fails to respond to sophisticated market demands or highlight Australia's diversity in region, growth, and product heritage. It is advertising a single dimension brand in a multidimensional market.

\section{Differentiated supply chain management}

One competitive option used to enhance regional identity revolves around differentiation through supply chain (SC) configuration, since supply chains are composed of organisations who contribute to the flow of products, information, and financials from source of supply eg. growers through the intermediaries (winery/bottling plant) to the distributor/retailer and finally to the end user (Min and Mentzer, 2004; Coyle, Bardi and Langley, 2003). Bringing together these organisations in such a manner as to develop existing networks of organizations into collaborative communities of supply (Sense and Clements, 2007) will greatly enhance regionally based R\&D, designed around the needs of the region with an end customer focus.

Designing and building this ideal supply chain is an achievable challenge. Our survey results suggest overwhelming (91\%) support and motivation for regional identification as a mechanism for brand development of premium products. This desire for competitive differentiation forms the framework for supply chain design. It also ignites collaboration between regional chain members such as growers and wineries because it places "emphasis on higher level organizational and process flexibility and coordination of 
processes across many sites”(Chandra and Kumar, 2000, p101) in this case within the regional boundaries.

The basis of competitive supply chain management is identity (brand) of product and strategic fit to customer base. In the instance of fine wines, producers have established their core competency and focused on producing regionally prominent quality wines of distinction. In turn, this has identified their niche customer segment as one that purchases wine primarily on quality and less on value.

From a commodity perspective, value return is the overriding focus for customers of retail-based organizations, such as supermarkets and retail wine warehouses, where commodity products thrive. Once the consumer market is determined, then design of the supply channel or distribution channel is established to deliver to the expectation of this pre-determined customer base. The value equation influences the price/benefit trade-off in the mind of the customer. This equation moves the quality focus to a price focus and turns the product to a commodity rather than a quality labeled or branded product. When products are purchased on price point, it is more 'value' and less 'brand' focused.

Supply chains can also be constructed on a quality product focus and a commodity focus concurrently. It is quite expected for organisations in the FMCG sector to operate a variety of supply chains for different customer segments. Normally at least one supply chain will be used for commodity type products or 'fighting brands'. These, as the label suggests, are used to compete with other producers for market share while still 
establishing some level of brand recognition. This strategy suggests that participating in both supply chains provides the production team with a broader customer base, whilst spreading risk, articulating reputation, and gaining a return at both the commodity and premium end of the market.

The role of any supply chain is to deliver the correct product or service bundle to the customer based on the agreed customer expectation. Already presented in this paper is the notion that the Australian wine industry has predominantly focused on the mass market for economies of scale and volume, driven by the retailer, at the expense of regionally identifiable, quality products crafted for the discerning market (customized product). The retailer will retain both the power and the margin when the product becomes a commodity due to producer reliance on retailer interface with the customer. This is the only case for commodity (price point driven) products. The power of the retailer in the supply chain is reduced when the product is customized to the non-volume niche markets.

Commodity driven chains are price sensitive and therefore are characterized by power/dependent relationships. They rely on the chain member who has the interface with the customer base. Unfortunately in the wine industry as in most FMCG sectors, this trade-off is often at the expense of the grower and the winery. Both the grower and winery take the majority of the risk and receive disproportionately small returns, as in figure 1. 
Figure 1: Commodity Chain Retailer/customer interface

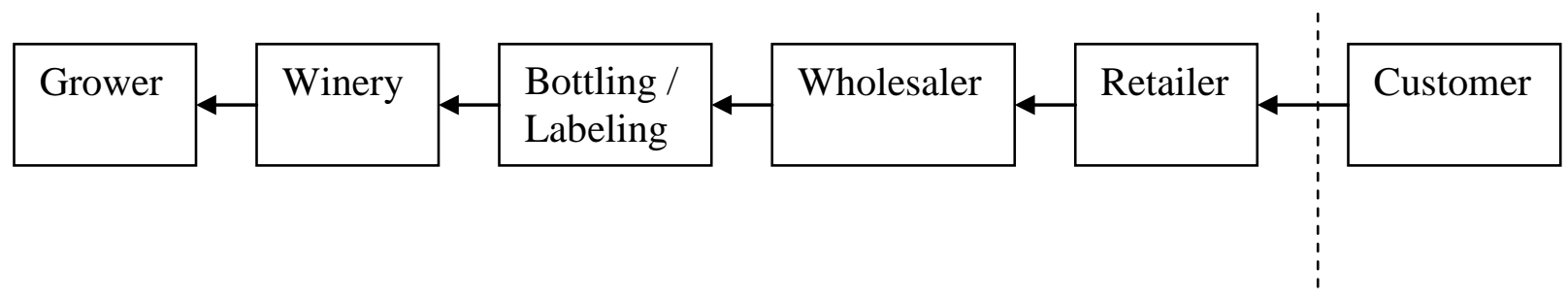

In niche market (customized product) chains, however, the production team, consisting of the grower and the winery, are able to position their product on non price value attributes, therefore influencing the distribution channels to market, as in figure 2.

Figure 2: Production team driven supply chain

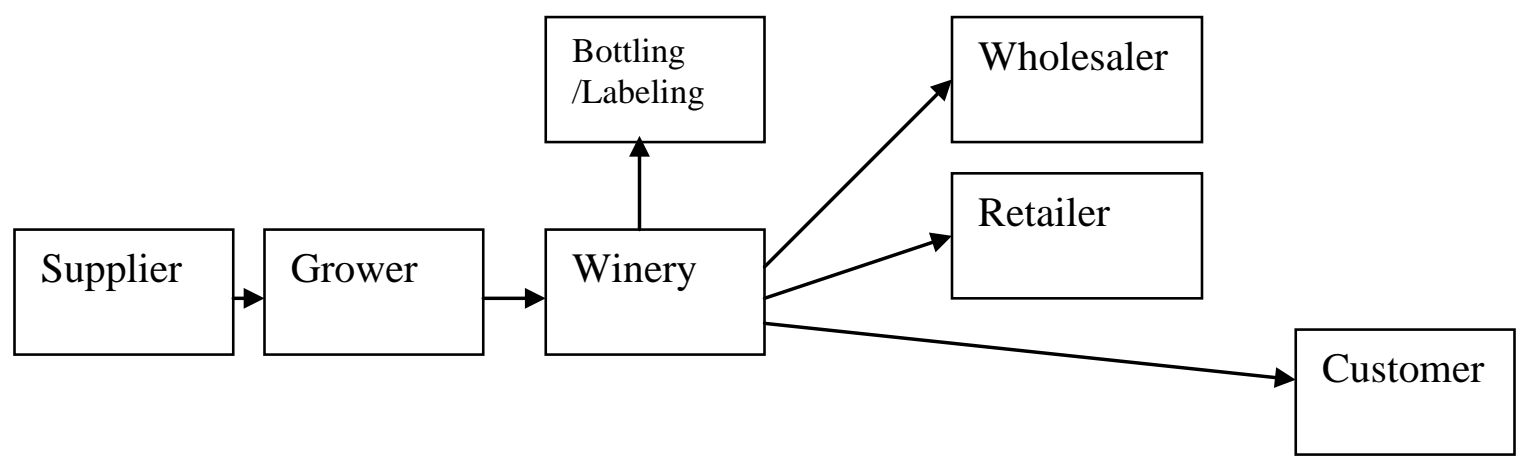

The development of niche, premium product supply chains will enhance the innovative practices of participants as they strive to attain flexibility whilst maintaining operational efficiency. These supply changes are conducive to creative thinking and collaboration, both of which develop relational bonds.

For supply chains to be effective in enabling product differentiation, they need to be composed of organisations with similar operational strategies. This means chain members 
should add value to the product distribution process. Forming co-operative buyer/seller (winery /grower) supply chain relationships enables organisations' to combine their individual strengths and unique resources (Whipple and Frankel, 2000) while leveraging the resources and skills of members along the chain (Min et al., 2005).

To achieve these regional-specific, quality-driven supply chains, reliable relationships need to develop. These supply chains rely on the sharing of real-time information. This is only achieved by organizations willing to collaborate for a common purpose, where all parties focus on the end customer, rather than the immediate transaction. Unfortunately tensions emerge when the winery/grower relationship focuses on the transaction. In a recent study of New Zealand winery/grower relationships (Forbes, Cohen and Clements, 2007) it was found that $68 \%$ of growers were concerned that their payment for grape quality was determined solely by the winery with $15 \%$ concerned that they were not paid a fair price for their product. Similar concerns were previously identified in Australia (Fraser, 2002) with 83\% of surveyed Australian growers unhappily accepting the price risk incurred through wineries deciding to delay their harvesting. Fraser (2003) also noted grower frustration with the imprecise measurement of grape quality, and its relationship to price arrangements, which provided excessive power to wineries in wine grape supply chains.

Innovative market supply chains strive to mutually develop a more equitable risk/reward mechanism at the winery/grower interface. This relationship becomes one of sharing information and risks/returns. These supply chains depend on an end customer strategic 
focus. They move away from the winery/grower transaction focus (price paid for product delivered) and focus on how their shared knowledge can position a premium product to a niche-focused customer, providing premium returns.

Embracing innovative supply chain management will enhance various relationship interfaces and provide more productive $\mathrm{R} \& \mathrm{D}$ focus and diffusion of regionally important knowledge. These new chains can enhance the flexibility of regions to respond to changing customer demand whilst maintaining a duel-strategy approach as both a commodity and premium product supply chain. This differentiated approach is critical for SME's to be competitive in a market dominated by corporate influence.

\section{Concluding remarks}

Each of the above initiatives of course underlines the differentiated responses that the Australian wine industry must adopt if it is to avoid being relegated to its supply status of the 1970s.

After establishing its credentials for innovative foresight throughout the 1990s, the industry allowed itself to be captured by the interests of its largest corporations. These corporations, justifiably for their own welfare, led the industry into a stable, nationalized, path dependency. It was a path dependency in which new production, R\&D, distribution and marketing strategies were fitted within the existing supply chain framework. The world's commodity markets had become the domain of Australian wine multinationals. 
Alternative routes of product identification that were emerging in Bordeaux, New Zealand and California were, and still are, perceived as a threat to this framework.

The Australian wine industry faces further depletion unless it can extricate itself from the 'iron cage' of commodification and embrace the cultural leadership being demonstrated by its most robust regional producers. There is no threat to the commodity market. There is no threat to Australia's ability to develop young, fruit-driven, blended wine for the world's non-discriminating drinkers. There currently exists, however, a rapidly closing window of opportunity for the industry to promote its differences, its variety, its regionality and heritage, and perhaps most importantly, its ability to produce fine wine. Only with the cultural acceptance and promotion of parallel but differentiated wine sectors can the industry move toward true maturity. 


\section{References}

- Akerman, P., (2007), 90pc of wine trade sinking in red ink, The Australian, 19 March.

- Anderson, K., (2004) Introduction, in The World's Wine Markets: Globalisation at Work' (Ed: Anderson, K.) Edward Elgar, UK, pp.3-10

- Astley, W.G. (1984). “Toward an appreciation of collective strategy”. Academy of Management Review, 9: 526-535

- Astley, W.G. (1985). "The two ecologies: population and community perspectives in organizational evolution”. Administrative Science Quarterly, 30: 224-241.

- Australian Broadcasting Corporation, Program transcript, http://www.abc.net.au/7.30/content/2006/s1629100.htm, Broadcast: 02/05/2006

- Australian Wine Online, (2007), Strategy 2025, http://www.winetitles.com.au/awol/overview/strategy2025/

- Aylward, D. (2006), Global Pipelines: Profiling successful SME exporters within the Australian wine industry, International Journal of Technology, Policy and Management, Vol 6, No.1, April. pp.49-65

- Barker, J., Lewis, N., and Moran, W., (2001), regulation and Development in the New Zealand Wine Industry, Journal of Wine Research, Vol.12, No.3, pp.199221

- Beeston, J., (1994), A Concise History of Australian Wine, Allen \& Unwin, London, pp. 4, 135, 33

- Benfratello, L., Piacenza, M, \& Sacchetto, S., (2004), Taste or Reputation: What Drives Market Prices in the Wine Industry? Estimation of a Hedonic Model for Italian Premium Wines, $2^{\text {nd }}$ Annual International industrial Organization Conference, Kellogg School of Management, Chicago, pp.1-5

- Beverland, M., (2005), Crafting Brand Authenticity: The Case of Luxury Wines, Journal of Management Studies, Vol. 42, no. 5, pp.1003-1029

- Chandra, C and Kumar, S. (2000), Supply chain management in theory and practice: a passing fad or a fundamental change? Industrial Management \& Data Systems, MCB University Press. 
- Coyle, J.J., Bardi, E.J. and Langley, C.J. Jr. (2003) The management of business logistics: A supply chain perspective ( $7^{\text {th }}$ Edition). Canada: South-Western Thompson Learning.

- Croser B. (2006), Waxing and whining, Masters of Wine Conference: Napa Valley, June.

- Croser B. 2004. Brand or authenticity. Australian and New Zealand Wine Industry Journal: 12-22.

- DiMaggio P, Powell W. 1991. The iron cage revisited: institutional isomorphism and collective rationality in organizational fields. In P DiMaggio, W Powell (Eds.), The New Institutionalism in Organizational Analysis. The University of Chicago Press: Chicago.

- Eales, J., and Binkley, J., (2003), Vertical Product Differentiation in Theory and Practice, Journal of Agricultural and Food Industrial Organization, Vol 1, 16, p.1

- Echikson W. 2004. Noble rot: A Bordeaux wine revolution. WW Norton \& Co: UK.

- Forbes, S., Cohen, D.A. and Clements, M.D. (2007) 'Independent grape grower and winery relationships: Is everything rosé in the New Zealand wine industry', Australian and New Zealand Wine Industry Journal, Vol. 22(1), pp. 47-52.

- Fraser, I. (2002). Survey shows dispute resolution lacking. Australian Viticulture, 6 (6), 68-79.

- Fraser, I. (2003). The role of contracts in wine grape supply coordination: An overview. Agribusiness Review, 11, Paper 5.

- Grape and Wine Research and Development Corporation, (2007), website accessed April, 2007, http://www.gwrdc.com.au/role.asp

- Greenwood R, Hinnings C. 1996. Understanding radical organizational change: bringing together the old and the new institutionalism. Academy of Management Review 21(4): 1025-1035

- Hannan M, Freeman J. 1984. Structural inertia and organizational change. American Sociological Review 49: 149-160.

- Hannan, M.T. and Freeman, J. (1989). Organizational Ecology. Cambridge: Harvard University Press.

- Hannan, M.T. and Freeman, J., (1984), Structural inertia and organizational change, American Sociological Review, vol.49, pp.149-160 
- Heijbroek, A. (2006), Time to invest in the idea of quality, Wine Business Magazine, pp.41-42

- Henry, P., 2006 Industry needs creative ideas, Wine Business Monthly, September, pp.26-29

- Johnson, H., 2006, Wine: A Life Uncorked, Weidenfeld \& Nicolson, London, pp.16, 35-45, 259-280

- Kaniovski, S., (2005) Product differentiation and competitive selection, Journal of Evolutionary Economics, Vol. 15, pp.567-580

- Kramer, M., (2007), Aussie wine cops a serve, The Age, March 27.

- Mariani, J., (2007), U.S. Wine Exports Surge 30 Percent in 2006, Led by California, Bloomberg Press, April 2.

- Min, S. and Mentzer, J.T., (2004). Developing and measuring supply chain management concepts. Journal of Business Logistics, 25(1), 63-99.

- Min, S., Roath, A., Daugherty, P., Genchev, S., Chen, H., Arndt, A. and Richey, R. (2005) 'Supply chain collaboration: What's happening?', TheInternational Journal of Logistics Management, Vol. 16(2), pp. 237-256.

- Narula and Zanfei (2005). “Globalization of innovation: the role of multinational enterprises”. In J. Fagerberg, D.C.Mowery and R.R. Nelson (eds.), The Oxford Handbook of Innovation, 318-345. Oxford: Oxford University Press.

- Pritchard, B. (1999). The regulation of grower-processor relations: A case study from the Australian wine industry. Sociologia Ruralis, 39 (2), 186-200.

- Ruef, M., (2004), For whom the bell tolls: ecological perspectives on industrial decline and resurgence, Industrial and Corporate Change, vol.13, no.1, pp. 61-89

- Schamel, G., (2003), A Dynamic Analysis of Regional and Producer Reputation for California Wine, OENOMETRICS X, the 2003 Annual Conference of the Vineyard Data Quantification Society, Budapest, Hungary, May 22-24.

- $\quad$ Sense, A.J and Clements, M.D. (In press for 2007, accepted on 16.04.2007) Learning to integrate: Supply chain re-conceptualized', International Journal of Learning and Change (Special issue on Learning in Supply Chains).

- Sharp, A., (2007) Wine exports up, but falling prices dent revenue, The Age Business, March 8.

- Supply Chain Review, (2007) Small wineries suffer in competitive overseas market, March 12 
- Taplin, I., (2006), Competitive pressures and strategic repositioning in the California premium wine industry, International Journal of Wine Marketing, Vol. 18, No. 1, pp.61-70

- Trist, E.L. (1977). “A concept of organizational ecology”. Australian Journal of Management, 2:161-175.

- Trist, E.L. (1983). "Referent organizations and the development of interorganizational domains”. Human Relations, 36: 269-284.

- Whipple, J.M. and Frankel, R. (2000) 'Strategic alliance success factors', Journal of supply chain management, Vol. 36(3), pp. 21-28.

- Wilson, T. (2004) Globalization, differentiation and drinking cultures, an anthropological perspective, Anthropology of Food, Issue 3, December, pp.2-16 Wine industry struggles to cope with grape glut, Reporter: Mike Sexton

- Winemakers Federation of Australia, Grape and Wine Research Development Corporation \& Australian Wine and Brandy Corporation (2006), Interviews carried out with organization representatives as part of the study. Adelaide.

- Winetitles, (2001) The Australian and New Zealand Wine Industry Directory, Adeaide, Winetitles Publications 